\title{
Detection of Surface-Linked Polychlorinated Biphenyls using Surface-Enhanced Raman Scattering Spectroscopy
}

Rindzevicius, Tomas; Barten, Jan; Vorobiev, Mikhail; Schmidt, Michael Stenbæk; Castillo, John J.; Boisen, Anja

Published in:

Vibrational Spectroscopy

Link to article, DOI:

10.1016/j.vibspec.2017.02.004

Publication date:

2017

Document Version

Peer reviewed version

Link back to DTU Orbit

Citation $(A P A)$ :

Rindzevicius, T., Barten, J., Vorobiev, M., Schmidt, M. S., Castillo, J. J., \& Boisen, A. (2017). Detection of Surface-Linked Polychlorinated Biphenyls using Surface-Enhanced Raman Scattering Spectroscopy. Vibrational Spectroscopy, 90, 1-6. https://doi.org/10.1016/j.vibspec.2017.02.004

\section{General rights}

Copyright and moral rights for the publications made accessible in the public portal are retained by the authors and/or other copyright owners and it is a condition of accessing publications that users recognise and abide by the legal requirements associated with these rights.

- Users may download and print one copy of any publication from the public portal for the purpose of private study or research.

- You may not further distribute the material or use it for any profit-making activity or commercial gain

- You may freely distribute the URL identifying the publication in the public portal 


\section{Detection of Surface-Linked Polychlorinated Biphenyls using Surface-Enhanced Raman}

\section{Scattering Spectroscopy}

Tomas Rindzevicius, ${ }^{*}$ a Jan Barten, ${ }^{\mathrm{b}}$ Mikhail Vorobiev, ${ }^{\mathrm{b}}$ Michael S. Schmidt, ${ }^{\mathrm{a}}$ John J. Castillo ${ }^{\mathrm{c}}$ and Anja Boisen, ${ }^{\mathrm{a}}$

${ }^{a^{*}}$ Technical University of Denmark, Department of Micro-and Nanotechnology, Ørsteds Plads, Building 345 east, 2800 Kgs. Lyngby, Denmark, e-mail: trin@nanotech.dtu.dk

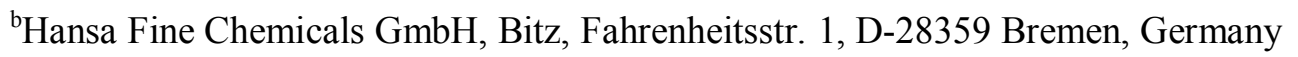

'Universidad Industrial de Santander, Grupo de Investigación en Bioquímica y Microbiología, Calle 9 carrera 27, Bucaramanga, Colombia. 


\section{Highlights}

- Analytical detection of toxic polychlorinated biphenyls (PCB) was possible using surfaceenhanced Raman scattering (SERS) spectroscopy.

- PCB77 compounds were chemically modified with a -SCH3 (PCB77-SCH3) group in order to improve the detection limit of PCBs.

- Our results point towards more efficient path for detecting different PCB congeners from real-life samples.

\footnotetext{
Abstract

We present an improved procedure for analytical detection of toxic polychlorinated biphenyls (PCB) using surface-enhanced Raman scattering (SERS) spectroscopy. A gold-capped silicon nanopillar substrate was utilized to concentrate PCB molecules within an area of high electromagnetic fields through formation of microsized nanopillar clusters, and consequently, so-called "hot spots" can be formed. In order to improve PCB detection limit, 3,3',4,4'-tetrachlorobiphenyl (PCB77) compounds were chemically modified with a $\mathrm{SCH}_{3}\left(\mathrm{PCB} 77-\mathrm{SCH}_{3}\right)$ group. Experimental and numerical analysis of vibrational modes showed only minor differences between standard PCB77 and $\mathrm{PCB} 77-\mathrm{SCH}_{3}$. Consequently, we observe significantly increased SERS signals for $-\mathrm{SCH}_{3}$ modified PCB77 while retaining most vibrational modes that characterize standard PCB77. Results point towards more efficient path for detecting different PCB congeners from real-life samples. We interpret the result as $\mathrm{PCB} 77-\mathrm{SCH}_{3}$ link to gold surface via sulfur atoms that facilitates accumulation of the modified PCB molecules on the metal surface. For similar SERS experimental conditions most spectral characteristics of PCB77 are identifiable down to concentrations of $\sim 10^{-5} \mathrm{M}$ while $\mathrm{PCB} 77-\mathrm{SCH}_{3}$ spectral fingerprint is retained in $\sim 10^{-8} \mathrm{M}$ range.
} 
Keywords: Polychlorinated biphenyls, PCB, toxic molecules, surface-enhanced Raman scattering, SERS detection, hot spots, gold nanopillars

\section{Introduction}

Polychlorinated biphenyls (PCBs) are a group of organic compounds that were manufactured by industry back in 1926 [1]. Today it is well known that PCBs cause a number of harmful effects [2] including cancer [3]. Although this toxic group of chemicals was banned in the 1970 s, they are still frequently found worldwide in environment [4, 5], animal-source food [6] and natural waters [7].

Conventional PCB detection methods are usually based on gas chromatography (GC) [8, 9] or mass spectroscopy (MS) [10] with reported detection limits for single PCB congeners down to 0.05-0.1 $\mathrm{ngL}^{-1}$ [11]. Even though these methods display excellent PCB discrimination and detection capabilities, they require considerable effort and time.

Recent progress towards new PCB detection schemes include electrochemical impedance sensing using a single-walled carbon nanotube [12], electrochemical magneto-immunosensor [13], changes in surface photovoltage of porous $\mathrm{ZnO}$ [14], assay based on immuno-polymerase chain reaction [15], attenuated total reflection Fourier-transform infrared (ATR-FTIR) spectroscopy [16], fluorescence [17, 18] and surface plasmon resonances (SPRs) in thin gold films $[19,20]$. In terms of detection speed, ease of handling and reliability there is still room for better PCB sensors. The aforementioned techniques have either practical limitations or target pure PCB congeners instead of realistic PCB mixtures compared to more powerful GC/MS methods [9]. On the other hand, the latter techniques require considerable effort, time and have limited mobility. Chobtang and co-workers have specifically outlined the need for real-time and on-site PCB sensing systems in order to make timely decisions [21]. 
Surface-enhanced Raman scattering (SERS) [22, 23] spectroscopy has extraordinary potential to discriminate target species down to single molecule level [24]. A number of studies have demonstrated that SERS-based detection of PCBs is feasible using silver nanorods [25], dendrites [26, 27], nanoparticle decorated $\mathrm{ZnO}$ nanorods [28] and nanosheet-assembled micro-hemispheres [29]. Zhou et al. showed that PCBs can be detected by SERS using Ag nanorods down to $10^{-8} \mathrm{~mol} / \mathrm{L}$ [30]. However, since all PCB SERS studies utilize pure, isolated PCB compounds results might be different when dealing with real-life samples. It is therefore important to also focus on techniques that allow to filter or concentrate PCBs on the metal surface. For example, Bantz and co-workers have utilized alkanethiol space-layers to concentrate PCBs at the surface of a SERS substrate [31]. Although partition-layers introduce background signal, the authors argued that PCB detection and discrimination can be significantly improved. Zhu and co-workers [32] have also utilized decanethiol self-assembled monolayers for detection of PCB77 and specifically outlined that the detection limit can be further improved if better bonding of PCB77 to the metal surface is achieved.

For SERS-based PCB detection methods concentration of PCB molecules in the vicinity of the noble metal surface is key [32]. The SERS enhancement factor approximately scales as $\left|E_{p} / E_{0}\right|^{4}$, where $E_{p}$ is the near-field generated by noble metal particles at the position of the molecular emitter, and $E_{0}$ is the electric component of the incident radiation. Since the SERS effect is a local phenomenon, large inelastic scattering signals can only be obtained when the target molecule is situated within narrow gaps between plasmonic particles - the so-called hot spots [33]. In this contribution, we suggest a procedure to effectively concentrate PCB molecules at a noble metal surface. In order to enhance affinity of PCB77 molecules towards nanostructured gold surface, the molecules were modified with a $-\mathrm{SCH}_{3}$ group. We compare strikingly similar spectral characteristics of standard PCB77 and modified PCB77 molecules and analyze vibrational modes using density functional theory (DFT) computational modelling method, which is in good agreement with the experimentally recorded spectra. We investigate evidence for formation of PCB77$\mathrm{SCH}_{3}$ molecular layers on the Au metal surface using gold-capped silicon nanopillar SERS substrates. Results indicate that it is considerably easier to detect $-\mathrm{SCH}_{3}$ modified $\mathrm{PCB} 77$ molecules compared to 
standard PCB77 when acquiring SERS spectra under identical experimental conditions. We show that the PCB detection limit can be significantly improved, which is of high practical importance not only for detecting different PCB congeners using SERS, but also for the development of new types of label-free nanoplasmonic sensors.

\section{Experimental}

\subsection{Synthesis of $\mathrm{PCB} 77-\mathrm{SCH}_{3}$}

First, we aim to employ a method to perform a controlled substitution of one $-\mathrm{Cl}$ by the $-\mathrm{SCH}_{3}$ group. This is important in order to systematically evaluate the obtained molecule using both theoretical and experimental methods. Due to this we synthesized a building block already containing this SMe-group and perform a coupling to obtain the $\mathrm{PCB} 77-\mathrm{SCH}_{3}$. This molecule was isolated in pure form and structure was investigated and confirmed by NMR prior to Raman and SERS analyses. Modified PCB77 molecules in this work were synthesized using 4-chloro-3-methylthioiodobenzene and 3,4-dichloroboronic acid blocks, see illustration in Figure 1(a). $4 \mathrm{~g}$ - 0.0141 Mol 4-chloro-3-methylthioiodobenzene, $3 \mathrm{~g}$ - 0.0155 Mol 3,4dichloroboronic acid and $4.1 \mathrm{~g}-0.0388 \mathrm{Mol} \mathrm{Na}_{2} \mathrm{CO}_{3}$ were dissolved in $22 \mathrm{ml}$ of water, $22 \mathrm{ml}$ of methanol and $90 \mathrm{ml}$ of toluene. After $10 \mathrm{~min}$ under $\mathrm{N}_{2}$-atmosphere $0.9 \mathrm{~g} \quad-0.00078$ Mol tetrakis(triphenylphospin)palladium $\left(\mathrm{Pd}\left(\mathrm{PPh}_{3}\right)_{4}\right)$ was added and stirred for $30 \mathrm{~h}$ at $80^{\circ} \mathrm{C}$. After cooling down this mixture was poured into $200 \mathrm{ml}$ of water and extracted 3x with ethyl acetate (EtOAc). Organic phase was washed with $5 \% \mathrm{NaHCO}_{3}$, water and $\mathrm{NaCl}$ solution. After drying over $\mathrm{Na}_{2} \mathrm{SO}_{4}$ and removal of all solvents the residue was purified by chromatography using silica gel and hexane as eluent to get $4,4^{\prime}, 3^{\prime}-$ trichloro-3-methyltiobiphenyl as white crystals. Sublimation at $88^{\circ} \mathrm{C}$. Yield: $3.3 \mathrm{~g}=77 \%$. ${ }^{1} \mathrm{H}$ NMR $\left(\mathrm{CDCl}_{3}\right): \delta=7.61(\mathrm{~d}, J=2.0 \mathrm{~Hz}, 1 \mathrm{H}), 7.51(\mathrm{~d}, J=8.3 \mathrm{~Hz}, 1 \mathrm{H}), 7.41(\mathrm{~d}, J=8.3 \mathrm{~Hz}, 1 \mathrm{H}), 7.36(\mathrm{dd}, J=8.4$, $2.1 \mathrm{~Hz}, 1 \mathrm{H}), 7.25(\mathrm{~s}, 1 \mathrm{H}), 7.21(\mathrm{dd}, J=8.4,2.1 \mathrm{~Hz}, 1 \mathrm{H}), 2.53(\mathrm{~s}, 3 \mathrm{H}) \mathrm{ppm}$. 
In Figure 1(b) we suggest another, a more practical procedure that can be potentially used with real life samples. In this procedure the treatment of PCB77 with large excess of MeSNa under harsh conditions is shown. Note, it is not clear at this point how many and which chlorine atoms can be substituted. In order to establish this, one needs to perform a purification and analysis of the mixture which is beyond the scope of this work. We suggest the following process guidelines for working with real life samples: a mixture of e.g. 3,3,4,4-tetrachlorobiphenyl and MeSNa ( 3.5:1) in sulfolane, heated up to $\sim 110{ }^{\circ} \mathrm{C}$ for $10-20 \mathrm{~h}$ under $\mathrm{N}_{2}$ atmosphere. After cooling down, the mixture can be poured into water and filtrated to get a crystalline powder.

\subsection{Fabrication of SERS substrates}

Gold metal coated silicon nanopillars were fabricated following the protocol in ref. [34]. The SERS substrate is produced using maskless lithography and the fabrication process essentially involves only two fabrication steps. First, silicon nanopillars were produced using $\mathrm{SF}_{6}$ and $\mathrm{O}_{2}$ reactive ion etching process. After the silicon etching cycle, the surface was further treated with the $\mathrm{O}_{2}$-plasma to remove fluorine and sulfur related products [41]. Second, $200 \mathrm{~nm}$ thick gold film was deposited using electron beam evaporation and the surface exhibited dark red color. Inspection in a scanning electron microscope (SEM) showed that the SERS substrate consisted of $\sim 500 \mathrm{~nm}$ in height gold-capped nanopillars that are roughly perpendicular to the silicon surface, see Figure 4(c). The gold cap is approximately ellipsoidal with average dimensions a $\approx 300 \mathrm{~nm}$ and $\mathrm{b} \approx 100 \mathrm{~nm}$ in height and width, respectively.

\subsection{UV-Vis, Raman and SERS measurements}

PCB No 77 compound (3,3',4,4'-tetrachlorobiphenyl, analytical standard) utilized in all the PCB77 related experiments was purchased from Sigma-Aldrich. The UV-Vis absorption spectra of PCB77 and PCB77-SCH 3 compounds were recorded in the range of 200-400 nm using Shimadzu UV-1800 UV-Vis spectrophotometer. Both PCB samples were prepared in isopropanol (IPA, $\mathrm{C}_{3} \mathrm{H}_{8} \mathrm{O}$ ) in the concentration of $10 \mu \mathrm{M}$. A baseline correction was made for both sample and reference cells, and the obtained UV-Vis spectra were normalized to unity for comparison, see results in Figure 1(c). 
Raman and SERS measurements were performed using Thermo Scientific DXR Raman Microscope. An optical microscope is coupled to a single grating spectrometer that delivers $5.0 \mathrm{~cm}^{-1} \mathrm{FWHM}$ spectral resolution and $2.0 \mathrm{~cm}^{-1}$ accuracy. Frequency-stabilized single mode diode laser operated at $780 \pm 0.2 \mathrm{~nm}$. All solid-state Raman and SERS spectra were recorded using 10x long working distance objective and laser powers of $5 \mathrm{~mW}\left(\sim 70 \mathrm{~kW} / \mathrm{cm}^{2}\right)$ and $0.1 \mathrm{~mW}\left(\sim 1.3 \mathrm{~kW} / \mathrm{cm}^{2}\right)$, respectively. Signal collection time was set to 5 seconds, unless stated otherwise. Solid-state Raman spectra were recorded from randomly oriented powdered samples deposited on a glass slide. For SERS measurements both $\mathrm{PCB} 77$ and $\mathrm{PCB} 77-\mathrm{SCH}_{3}$ compounds were dissolved in IPA using magnetic stirring $(12 \mathrm{~h})$. The PCB concentrations ranged from $5 \times$

$10^{-3}$ down to $5 \times 10^{-8}$. The SERS substrates were then immersed into different PCB solutions of varying concentrations for $3 \mathrm{~h}$, rinsed with IPA and left for drying.

IPA solvent drying groups Au nanopillars together into microsized clusters which is important for obtaining high SERS signals [34], see schematic illustration and corresponding SEM images in Figure 4. Since larger Au nanopillar clusters increase SERS signal intensity [41], IPA solvent was found to be more effective in clustering Au nanopillars compared to e.g. tetrahydrofuran (THF) which is an organic liquid with lower viscosity. However, PCB77 molecules were also dissolved in THF for comparison (1 mM) and the recorded SERS spectral features were similar to the ones obtained using IPA.

\subsection{Computational methods}

All numerical calculations were performed using the program package Gaussian 09 [36]. The vibrational frequencies and Raman intensities were obtained numerically. The ground-state molecular structures were optimized utilizing density functional theory (DFT) calculations using the hybrid functional B3LYP [35, $37,38]$ and the standard 6-31G* basis set. In order to correct for systematic errors, all computed frequencies were scaled by a factor of 0.9614 according to ref. [39]. The GaussSum 3.0 program was used to produce theoretical spectra [40].

\section{Results and discussion}




\subsection{UV-Vis absorption and Raman scattering of $\mathrm{PCB} 77$ and $\mathrm{PCB} 77-\mathrm{SCH}_{3}$}

The obtained UV-Vis absorption spectra of $\mathrm{PCB} 77$ and modified $\mathrm{PCB} 77-\mathrm{SCH}_{3}$ are shown in Figure 1(c). Both PCBs display characteristic UV-Vis spectra dominated by a main-band at $\lambda_{1, \max }=213 \mathrm{~nm}$ which is attributed to resonance in the aromatic ring, i.e. the benzenoid skeleton, and is generally observed for all 209 PCB congeners [42]. The second strong absorption band found at $\lambda_{2, \max }=261$ and $288 \mathrm{~nm}$ for PCB77 and $\mathrm{PCB} 77-\mathrm{SCH}_{3}$, respectively. The band is attributed to conjugation between the phenyl groups and the position of the band varies for different PCB congeners. The $\sim 30 \mathrm{~nm}$ shift is consistent with UV-Vis spectral changes observed for adjacent PCB congeners, e.g. compare absorption spectra of PCB76 and PCB77 in ref. [42].

Before we analyze vibrational modes of modified PCB77 molecule, it is worthwhile to identify six distinct experimentally observed bands of PCB77 in the $1600-600 \mathrm{~cm}^{-1}$ spectral region. The calculated and experimental Raman spectra of standard PCB77 are shown in Figure 2(a) and the insets show molecular structures. Results are in good agreement with the previously published data [31]. The $400-700 \mathrm{~cm}^{-1} \mathrm{spectral}$ region mainly contains Raman modes associated with $\mathrm{C}-\mathrm{Cl}$ stretch and relative motions of two benzene rings, where the strongest band is at $676 \mathrm{~cm}^{-1}$. Based on our calculations, this experimentally observed band is dominated by deformation of benzene rings and $\mathrm{C}-\mathrm{Cl}$ bond stretching. The $1030 \mathrm{~cm}^{-1}$ band is related to motions of benzene rings (ring breathing), the 1136 and $1245 \mathrm{~cm}^{-1}$ are dominated by $\mathrm{C}-\mathrm{H}$ bending motions, and $1297 \mathrm{~cm}^{-1}$ band is attributed to biphenyl C-C bridge stretching motion. The strongest vibrational mode at $1597 \mathrm{~cm}^{-1}$ is related to symmetric in-plane stretching of benzene rings, see calculated vibrational amplitudes and frequencies in Figure 3.

Whereas PCB77 molecule has been studied experimentally and theoretically [31, 41], to the best of our knowledge there are no previous Raman investigations of $-\mathrm{SCH}_{3}$ modified PCB77 that enables link to the noble metal surface via sulfur atoms. As can be seen from Figure 2(b), the experimental solid state spectrum of $\mathrm{PCB} 77-\mathrm{SCH}_{3}$ shows no pronounced differences in comparison to standard PCB77. In the $1600-400 \mathrm{~cm}^{-}$ ${ }^{1}$ spectral region all vibrational modes characteristic to $\mathrm{PCB} 77$ are preserved. One noticeable change is the reduced relative intensity of the Raman band at $1297 \mathrm{~cm}^{-1}$ (biphenyl C-C bridge stretching) which is also 
well reflected in the calculated spectrum. In the $1600-400 \mathrm{~cm}^{-1}$ range, positions of the most intense Raman bands of PCB77 and PCB77-SCH 3 are within $\sim 3 \mathrm{~cm}^{-1}$, Figure 2. Our calculations show that the 400-700 $\mathrm{cm}^{-1}$ region of $\mathrm{PCB} 77-\mathrm{SCH}_{3}$ molecule is dominated by deformation of benzene rings, $\mathrm{C}-\mathrm{Cl}$ and $\mathrm{C}-\mathrm{S}$ (643 $\mathrm{cm}^{-1}$ ) bond stretching motions. Specifically, the experimentally observed $677 \mathrm{~cm}^{-1}$ band is related to deformation of one benzene ring and $\mathrm{C}-\mathrm{Cl}$ bond stretching, see Figure 2(b). In case of PCB77 molecule, the $676 \mathrm{~cm}^{-1}$ mode involves deformation of both benzene rings and $\mathrm{C}-\mathrm{Cl}$ stretching. The 1031 and $1134 \mathrm{~cm}^{-}$ ${ }^{1}$ bands are attributed to stretching motions of benzene rings, and the atomic displacement in these modes is similar to the standard PCB77. The 1242 and $1297 \mathrm{~cm}^{-1}$ vibrational patterns are also comparable to PCB77, and are dominated by $\mathrm{C}-\mathrm{H}$ wagging and biphenyl C-C bridge stretching motions. Finally, the most pronounced vibrational band at $1595 \mathrm{~cm}^{-1}$ is attributed to symmetric stretching of benzene rings, and the motion is particularly dominated by one benzene ring, see summarized data in Figure 3(c).

\subsection{SERS of $P C B 77$ and $P C B 77-\mathrm{SCH}_{3}$}

In Figure 4(a)-(b) the SERS detection principle utilizing gold-capped silicon nanopillars for standard and $-\mathrm{SCH}_{3}$ modified PCB77 is schematically illustrated. In the PCB77 case, the metal molecule link is not expected to occur, and therefore microsized clusters of Au nanopillars encapsulate fewer random PCB77 molecules, Figure 4(a). SERS spectra of PCB77 are shown in Figure 5. The largest difference due to the presence of the gold metal surface was observed for the Raman mode at $1297 \mathrm{~cm}^{-1}$. In the case of SERS measurements, the mode is now found at $1280 \mathrm{~cm}^{-1}\left(\sim 17 \mathrm{~cm}^{-1}\right.$ shift $)$, see Figure 3(c) for comparison. The SERS measurements using different concentrations of PCB77 ranging from $5 \times 10^{-3}$ to $5 \times 10^{-6} \mathrm{M}$ show that the Raman spectral characteristics diminish and are essentially not visible in the $\mu \mathrm{M}$ concentration range. Due to low solubility of PCB77 in IPA, we have verified the result using a moderately polar THF solvent [31] that can be used to effectively dissolve PCB77. SERS spectra of PCB77 and detection limit using THF were similar to the result shown in Figure 5.

For the modified $\mathrm{PCB} 77$ case, the $-\mathrm{SCH}_{3}$ group is expected to improve the $\mathrm{PCB}$ affinity towards the $\mathrm{Au}$ metal film, see schematic illustration in Figure 4(b). An increased SERS signal can be observed because 
higher number of PCB molecules are now concentrated within the high electromagnetic field area, i.e. close to the Au metal surface. The SERS spectra of $\mathrm{PCB} 77-\mathrm{SCH}_{3}$ with concentrations varying from $5 \times 10^{-3}$ down to $5 \times 10^{-8} \mathrm{M}$ are presented in Figure 6 and are very similar to the solid state vibrational pattern shown in Figure 2. Contrary to the PCB77 case, the entire molecular fingerprint of $\mathrm{PCB} 77-\mathrm{SCH}_{3}$ is preserved down to the $\sim 10^{-8} \mathrm{M}$ regime. Chemical stability of the modified PCB77 molecule on the gold surface was verified by monitoring SERS spectra for $3 \mathrm{~min}$ prior to acquiring the signal. No significant signs of transient effects similar to the ones observed e.g. for $2,2^{\prime}: 5^{\prime}, 2^{\prime}$--terthiophene $[34,37]$ were identified.

Comparison of the scattering intensity evolution of most intense Raman bands for standard $\left(1589 \mathrm{~cm}^{-1}\right)$ and modified PCB77 $\left(1586 \mathrm{~cm}^{-1}\right)$ are shown in Figure 7. The $1586 \mathrm{~cm}^{-1}$ PCB77 band is rapidly decreasing in intensity and the detection limit for current experimental conditions is $\sim 10^{-6} \mathrm{M}$. For the same concentration range the $\mathrm{PCB} 77-\mathrm{SCH}_{3}$ Raman band displays $\sim 4$ times higher intensity and all 6 characteristic vibrational modes are clearly identifiable, see Figure 6. A slight dip in the SERS intensity is observed for modified PCB77 at $\sim 10^{-3} \mathrm{M}$, see Figure 7. This is probably due to a reduced Au NP leaning which decreases the SERS signal intensity. Similar effect was observed for multilayer folic acid surface coverages using Ag $\mathrm{NP}$ structures [43]. Results from Figure 7 indicate that by modifying $\mathrm{PCB} 77$ with $-\mathrm{SCH}_{3}$ group the detection limit can be significantly improved, and is close to $\sim 10^{-8} \mathrm{M}$ which is due to a more effective concentration of PCB molecules on the noble metal surface.

\section{Conclusions}

According to the present study, an improved procedure based on a gold-capped silicon nanopillar substrate could be successfully employed for detecting toxic polychlorinated biphenyls (PCB) using surface-enhanced Raman scattering (SERS) spectroscopy. Upon binding of $\mathrm{S}-\mathrm{CH}_{3}$ modified PCB, the $\mathrm{Au}-$ PCB77 interaction significantly increases the SERS signal intensity in comparison to unmodified PCB77. We interpret this as an effective concentration of analyte molecules within the high electromagnetic field area, i.e. hot spots. A complete molecular fingerprint of $\mathrm{PCB} 77-\mathrm{SCH}_{3}$ was preserved down to $\sim 10^{-7} \mathrm{M}$. The 
estimated detection limit is $\sim 10^{-8} \mathrm{M}$ while using the same experimental setting the detection limit for standard PCB77 was $\sim 10^{-6} \mathrm{M}$.

The detection limit of standard PCB77 can of course be further improved by optimizing the experimental conditions or employing SERS signal mapping techniques [40]. However, these kind of techniques should also further improve the detection limit of $\mathrm{PCB} 77-\mathrm{SCH}_{3}$ in comparison to $\mathrm{PCB} 77$. Herein we employed a simple experimental set-up for comparison and to demonstrate straightforward PCB detection benefits when forming a PCB-metal link. It is of practical importance to develop on-site PCB detection method capable of concentrating different PCB types because real-life samples contain mixtures of PCB congeners (209 in total). We suggest one PCB modification procedure that can be adopted to simultaneously target different PCB congeners in real-life samples, see process guidelines in the experimental methods section and Figure 1(b). Real-life PCB-containing samples can have several appearances. Due to this an individual workup is required and solids must be powdered. For example, rubberlike material can be powdered using liquid nitrogen treatment, and in general all samples should be extracted with hydrocarbons e.g. in a Soxhlet apparatus with hexane. Removal of solvent gives crude material which can be treated with MeSNa without any further purification. The method could potentially be used on-site to extract different PCBs from relevant samples prior to SERS measurements. The SERS measurements could be performed using handheld Raman spectrometers that progressively are becoming smaller, better and cheaper [44].

\section{Acknowledgments}

This work has been funded by the NAPLAS project, Sapere Aude (The Danish Council for Independent Research). Authors would also like to acknowledge financial support from the European Research Council, Proof of Concept grant (THOR project, nr. 713474). Authors also acknowledge support from the European Research Council under the European Union's Seventh Framework Programme (FP7/2007-2013) Grant no. 320535-HERMES and the IDUN Center of Excellence funded by the Danish National Research Foundation (grant no. DNRF122) and Villum Fonden (Grant No. 9301). 


\section{References}

[1] Thomas G.O.; Sven Erik J.; Brian F. Polychlorinated biphenyls. In Encyclopedia of Ecology; Academic Press: Oxford, UK, 2008; pp. 2872-2881.

[2] The 12 initial POPs under the Stockholm Convention. http://chm.pops.int/Convention/ThePOPs/The12InitialPOPs (accessed Jan 28, 2015).

[3] Golden, R.; Doull, J.; Waddell, W.; Mandel, J. Potential human cancer risks from exposure to PCBs: a tale of two evaluations. Crit. Rev. Toxicol. 2003, 33, 543-580.

[4] Li, Y. F.; Harner, T.; Liu, L.; Zhang, Z.; Ren, N. Q.; Jia, H.; Ma, J.; Sverko, E. Polychlorinated Biphenyls in Global Air and Surface Soil: Distributions, Air-Soil Exchange, and Fractionation Effect. Environ. Sci. Technol. 2010, 44, 2784-2790.

[5] Rodenburg, L. A.; Guo, J.; Du, S.; Cavallo, G. L. Evidence for unique and ubiquitous environmental sources of 3,3'-dichlorobiphenyl (PCB 11). Environ. Sci. Technol. 2010, 44, 2816-2821.

[6] Ahmed, F. E. Analysis of polychlorinated biphenyls in food products. TrAC Trends Anal. Chem. 2003, 22, 170-185.

[7] Swackhamer, D. L.; Hites, R. A. Occurrence and bioaccumulation of organochlorine compounds in fishes from Siskiwit Lake, Isle Royale, Lake Superior. Environ. Sci. Technol. 1988, 22, 543-548.

[8] Zabelina, O. N.; Saloutin, V. I.; Chupakhin, O. N. Analysis of Polychlorinated Biphenyl Mixtures by Gas Chromatography. J. Anal. Chem. 2010, 65, 1098-1108.

[9] Nikonova, A. A.; Gorshkov, A. G. Rapid Chromatography for the Determination of Polychlorinated Biphenyls by GC-MS in Environmental Monitoring. Anal. Lett. 2011, 44, 1290-1300.

[10] Ingelido, A. M.; Brambilla, G.; Abballe, A.; Domenico, A. D.; Fulgenzi, A. R.; Iacovella, N.; Iamiceli, A. L.; Valentini, S.; De Felip, E. PCDD, PCDF, AND DL-PCB analysis in food: performance 
evaluation of the high-resolution gas chromatography/low-resolution tandem mass spectrometry technique using consensus-based samples. Rapid Commun. Mass Spectrom. 2012, 26, 236-242.

[11] Wang, Y.; Li, Y.; Zhang, J.; Xu, S.; Yang, S.; Sun, C. A novel fluorinated polyaniline-based solidphase microextraction coupled with gas chromatography for quantitative determination of polychlorinated biphenyls in water samples. Anal. Chim. Acta. 2009, 646, 78-84.

[12] Wei, Y.; Kong, L. T.; Yang, R.; Wang, L.; Liu, J. H.; Huang, X. J. Electrochemical impedance determination of polychlorinated biphenyl using a pyrenecyclodextrin-decorated single-walled carbon nanotube hybrid. Chem. Commun. 2011, 47, 5340-5342.

[13] Centi, S.; Silva, E.; Laschi, S.; Palchetti, I.; Mascini, M. Polychlorinated biphenyls (PCBs) detection in milk samples by an electrochemical magneto-immunosensor (EMI) coupled to solid-phase extraction (SPE) and disposable low-density arrays. Anal. Chim. Acta. 2007, 594, 9-16.

[14] Li, M.; Meng, G.; Huang, Q.; Yin, Z.; Wu, M.; Zhang, Z.; Kong, M. Prototype of a porous ZnO SPV-based sensor for PCB detection at room temperature under visible light illumination. Langmuir. 2010, 26, 13703-13706.

[15] Chen, H. Y.; Zhuang, H. S. Real-time immune-PCR assay for detecting PCBs in soil samples. Anal. Bioanal. Chem. 2009, 394, 1205-12011.

[16] Llabjani, V.; Trevisan, J.; Jones, K. C.; Shore, R. F.; Martin, F. L. Binary mixture effects by PBDE congeners $(47,153,183$, or 209$)$ and PCB congeners (126 or 153) in MCF-7 cells: biochemical alterations assessed by IR spectroscopy and multivariate analysis. Environ. Sci. Technol. 2010, 44, 3992-3998.

[17] Wang, M.; Meng, G.; Huang, Q.; Li, M.; Li, Z.; Tang, C. Fluorescence detection of trace PCB101 based on PITC immobilized on porous AAO membrane. Analyst. 2011, 136, 278-281. 
[18] Zhuang, H.; Ye, Q.; Chen, H. Detection of PCB77 by Antibody-Coated Competitive Fluorescent Quantitative Immuno-PCR Using Molecular Beacon. Anal. Lett. 2009, 42, 2774-2792.

[19] Shimomura, M.; Nomura, Y.; Zhang, W.; Sakino, M.; Lee, K. H.; Ikebukuro, K.; Karube, I. Simple and rapid detection method using surface plasmon resonance for dioxins, polychlorinated biphenyls and atrazine. Anal. Chim. Acta. 2001, 434, 223-230.

[20] Hong, S.; Kang, T.; Oh, S.; Moon, J.; Choi, I.; Choi, K.; Yi, J. Label-free sensitive optical detection of polychlorinated biphenyl (PCB) in an aqueous solution based on surface plasmon resonance measurements. Sens. Actuators B. 2008, 134, 300-3006.

[21] Chobtang, J.; de Boer, J. J. M.; Hoogenboom, R. L. A. P.; Haasnoot, W.; Kijlstra, A.; Meerburg, B. G. The Need and Potential of Biosensors to Detect Dioxins and Dioxin-Like Polychlorinated Biphenyls along the Milk, Eggs and Meat Food Chain. Sensors. 2011, 11, 11692-11716.

[22] Jeanmaire, D. L.; Van Duyne, R. P. Surface Raman electrochemistry. Part 1. Heterocyclic, aromatic and aliphatic amines adsorbed on the anodized silver electrode. J. Electroanal. Chem. 1977, 84, 1-20.

[23] Moskovits, M. Surface-enhanced spectroscopy. Rev. Mod. Phys. 1985, 57, 783.

[24] Xu, H.; Bjerneld, E. J.; Kall, M.; Borjesson, L. Spectroscopy of Single Hemoglobin Molecules by Surface enhanced Raman scattering. Phys. Rev. Lett. 1999, 83, 4357-4360.

[25] Zhou, Q.; Yang, Y.; Ni, J.; Li, Z.; Zhang, Z. Rapid Recognition of Isomers of Monochlorobiphenyls at Trace Levels by Surface-Enhanced Raman Scattering Using Ag Nanorods as a Substrate. Nano Res. 2010, 3, 423-428.

[26] Gutes, A.; Carraro, C.; Maboudian, R. Silver dendrites from galvanic displacement on commercial aluminum foil as an effective SERS substrate. J. Am. Chem. Soc. 2010, 132, 1476-1477. 
[27] Yang, Y.; Meng, G. Ag dendritic nanostructures for rapid detection of polychlorinated biphenyls based on surface-enhanced Raman scattering effect. J. Appl. Phys. 2010, 107, 044315.

[28] Tang, H.; Meng, G.; Huang, Q.; Zhang, Z.; Huang, Z.; Zhu, C. Arrays of Cone-Shaped ZnO Nanorods Decorated with Ag Nanoparticles as 3D surface-Enhanced Raman Scattering Substrates for Rapid Detection of Trace Polychlorinated Biphenyls. Adv. Funct. Mater. 2012, 22, 218-224.

[29] Zhu, C.; Meng, G.; Huang, Q.; Zhang, Z.; Xu, Q.; Liu, G.; Huang, Z.; Chu, Z. Ag nanosheetassembled micro-hemispheres as effective SERS substrates. Chem. Commun. 2011, 47, 2709-2711.

[30] Zhou, Q.; Yang, Y.; Ni, J.; Li, Z.; Zhang, Z. Rapid detection of 2, 3, 3', 4, 4'-pentachlorinated biphenyls by silver nanorods-enhanced Raman spectroscopy. Phys. E. 2010, 42, 1717-1720.

[31] Bantz, K. C.; Haynes, C. L. Surface-enhanced Raman scattering detection and discrimination of polychlorinated biphenyls. Vibrational Spectroscopy. 2009, 50, 29-35.

[32] Zhu, C.; Meng, G.; Huang, Q.; Huang, Z. Vertically aligned Ag nanoplate-assembled film as a sensitive and reproducible SERS substrate for the detection of PCB-77. J. Hazard. Mater. 2012, 211-212, 389-395.

[33] Xu, H.; Aizpurua, J.; Kall, M.; Apell, P. Electromagnetic contributions to single-molecule sensitivity in surface-enhanced Raman scattering. Phys. Rev. E. 2000, 62, 4318-4324.

[34] Schmidt, M. S.; Hubner, J.; Boisen, A. Large Area Fabrication of Leaning Silicon Nanopillars for Surface Enhanced Raman Spectroscopy. Adv. Mater. 2012, 24, OP11-OP18.

[35] Svedberg, F.; Alaverdyan, Y.; Johansson, P.; Kall, M. Raman spectroscopic studies of terthiophenes for molecular electronics. J. Phys. Chem. B. 2006, 110, 25671-25677.

[36] Frisch, M. J.; Trucks, G. W.; Schlegel, H. B.; Scuseria, G. E.; Robb, M. A.; Cheeseman, J. R.; Scalmani, G.; Barone, V.; Mennucci, B.; Petersson, G. A.; Nakatsuji, H.; Caricato, M.; Li, X.; Hratchian, 
H. P.; Izmaylov, A. F.; Bloino, J.; Zheng, G.; Sonnenberg, J. L.; Hada, M.; Ehara, M.; Toyota, K.; Fukuda, R.; Hasegawa, J.; Ishida, M.; Nakajima, T.; Honda, Y.; Kitao, O.; Nakai, H.; Vreven, T.; Montgomery, Jr., J. A.; Peralta, J. E.; Ogliaro, F.; Bearpark, M.; Heyd, J. J.; Brothers, E.; Kudin, K. N.; Staroverov, V. N.; Kobayashi, R.; Normand, J.; Raghavachari, K.; Rendell, A.; Burant, J. C.; Iyengar, S. S.; Tomasi, J.; Cossi, M.; Rega, N.; Millam, J. M.; Klene, M.; Knox, J. E.; Cross, J. B.; Bakken, V.; Adamo, C.; Jaramillo, J.; Gomperts, R.; Stratmann, R. E.; Yazyev, O.; Austin, A. J.; Cammi, R.; Pomelli, C.; Ochterski, J. W.; Martin, R. L.; Morokuma, K.; Zakrzewski, V. G.; Voth, G. A.; Salvador, P.; Dannenberg, J. J.; Dapprich, S.; Daniels, A. D.; Farkas, Ö.; Foresman, J. B.; Ortiz, J. V.; Cioslowski, J.; Fox, D. J. Gaussian 09, Revision A.1; Gaussian Inc.: Wallingford, CT, 2009.

[37] Becke, A. D. Density-functional thermochemistry. III. The role of exact exchange. J. Chem. Phys. $1993,98,5648-5652$.

[38] Alaverdyan, Y.; Johansson, P.; Kall, M. Photo-induced transformations in 2,2':5',2' '-terthiophene thin films on silver. Phys. Chem. Chem. Phys. 2006, 8, 1445-1450.

[39] Scott, A. P.; Radom, L. Harmonic Vibrational Frequencies: An Evaluation of Hartree-Fock, Møller-Plesset, Quadratic Configuration Interaction, Density Functional Theory, and Semiempirical Scale Factors. J. Phys. Chem. 1996, 100, 16502-16513.

[40] O’Boyle, A.; Tenderholt, L.; Langner, K. Cclib: A library for package-independent computational chemistry algorithms. J. Comp. Chem. 2008, 29, 839-845.

[40] Lai, Y.; Pan, W.; Ni, S.; Zhang, D.; Zhan, J. Theoretical evaluation of the configurations and Raman spectra of 209 polychlorinated biphenyl congeners. Chemosphere. 2011, 85, 412-417.

[41] Wu, K.; Rindzevicius, T.; Schmidt, M. S.; Mogensen, K. B.; Hakonen, A.; Boisen, A. Wafer-Scale Leaning silver Nanopillars for Molecular Detection at Ultra-Low Concentrations. J. Phys. Chem. C 2015, $119,2053-2062$. 
[42] Andersson, P. L.; Haglund, P.; Tysklind, M. Ultraviolet absorption spectra of all 209 polychlorinated biphenyls evaluated by principal component analysis. Fresenius J. Anal. Chem. 1997, 357, 1088-1092.

[43] Castillo J. J.; Rindzevicius, T.; Wu, K.; Rozo, C.; Schmidt, M.; Boisen A. Silver-capped silicon nanopillar platforms for adsorption studies of folic acid using surface enhanced Raman spectroscopy and density functional theory. J. Raman Spect. 2015, 46, 1087-1094.

[44] Lin, D.; Manara, D.; Lindqvist-Reis, P.; Fanghänel, T. The use of different dispersive Raman spectrometers for the analysis of uranium compounds. Vibrat. Spect. 2014, 73, 102-110. 


\section{Figure captions}

Fig. 1. (a) Illustration of $\mathrm{PCB} 77-\mathrm{SCH}_{3}$ synthesis steps. In (b) an alternative method for working with real-life samples is suggested. PCB77 reaction with sodiummethanethiolate is shown where one or more chlorine groups can be substituted with $-\mathrm{SCH}_{3}$ groups.

(c) UV-Vis absorption spectra of PCB77 $\left(10^{-5} \mathrm{M}\right)$ and $\mathrm{PCB}^{\mathrm{P}} 7-\mathrm{SCH}_{3}\left(10^{-5} \mathrm{M}\right)$, obtained using the method shown in (a)).

Fig. 2. Experimental and calculated Raman spectra for PCB77 (a) and $-\mathrm{SCH}_{3}$ group modified PCB77 molecules, (b). Insets show the corresponding molecular structures.

Fig. 3. Comparison of calculated vibrational frequencies $\left(\mathrm{cm}^{-1}\right)$ and amplitudes for the observed Raman active PCB77 and PCB77-SCH 3 modes, (a) and (b) respectively. Optimized molecular structures were calculated at the B3LYP/6-31G ${ }^{*}$ level. In (c) the most intense Raman modes of PCB77 and $\mathrm{PCB} 77-\mathrm{SCH}_{3}$ in the solid state, SERS and in theory are shown.

Fig. 4. Schematic comparison of the SERS-based PCB detection principles utilizing $\sim 500 \mathrm{~nm}$ tall gold-capped Si nanopillars on $200 \mathrm{~nm}$ thick gold film. Average pillar head dimensions are $~ 300$ and $\sim 100 \mathrm{~nm}$ in height and width, respectively. Solvent drying forms nanopillar clusters and encapsulates standard PCB77, (a), and $-\mathrm{SCH}_{3}$ modified PCB77 molecules, (b). In (c) representative SEM images illustrate the clustering step of gold-capped silicon nanopillars.

Fig. 5. Representative SERS spectra of PCB77 at concentrations of $5 \times 10^{-3}-5 \times 10^{-6} \mathrm{M}$. The spectra were recorded for $5 \mathrm{~s}$ at a laser power of $0.1 \mathrm{~mW}$. All spectra have been vertically offset.

Fig. 6. Representative SERS spectra of gold metal surface bonded $\mathrm{PCB} 77-\mathrm{SCH}_{3}$ at concentrations of $5 \times 10^{-3}-5 \times 10^{-8} \mathrm{M}$. The spectra were recorded for $5 \mathrm{~s}$ at a laser power of $0.1 \mathrm{~mW}$. All spectra have been vertically offset. 
Fig. 7. Comparison of integrated intensities of Raman active modes at varying concentrations for PCB77 (1589 and $1137 \mathrm{~cm}^{-1}$ ) and PCB77-SCH 3 (1586 and $1128 \mathrm{~cm}^{-1}$ ). Each data point corresponds to an averaged intensity from 10 different measurement positions. All spectra were recorded for $5 \mathrm{~s}$ at a laser power of $0.1 \mathrm{~mW}$. 


\section{Figure 1}<smiles>CSc1ccc(-c2ccc(Cl)c(Cl)c2)cc1Cl</smiles>

(b)

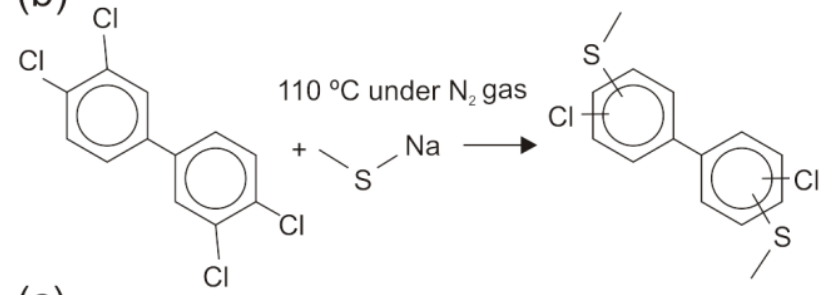

(c)

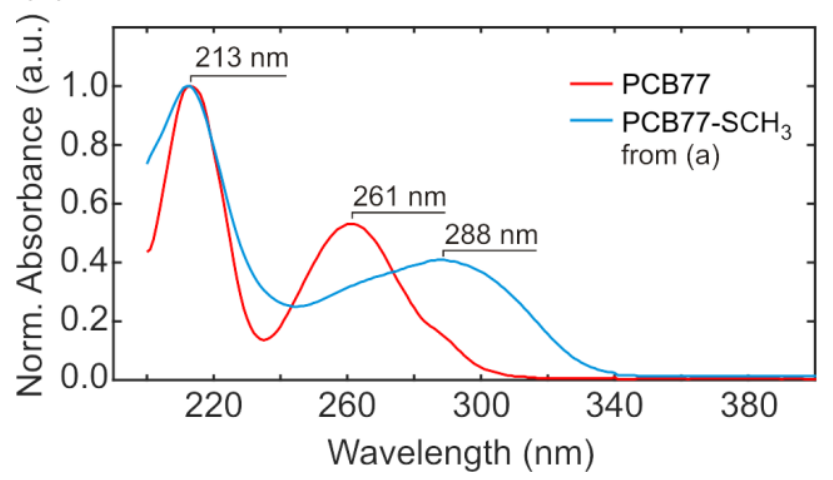


Figure 2
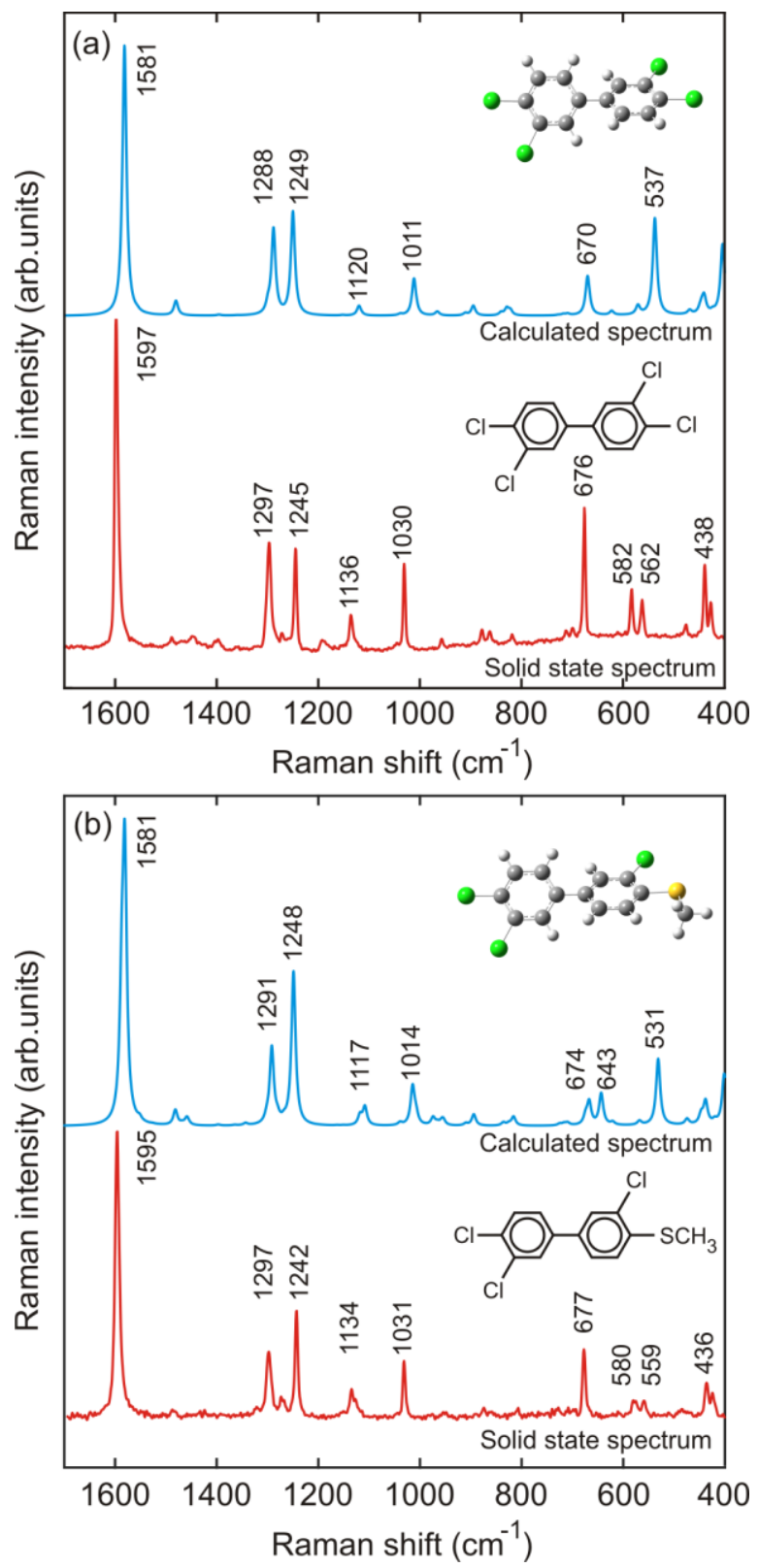


\section{Figure 3}

(a) РСB77

1288

1249
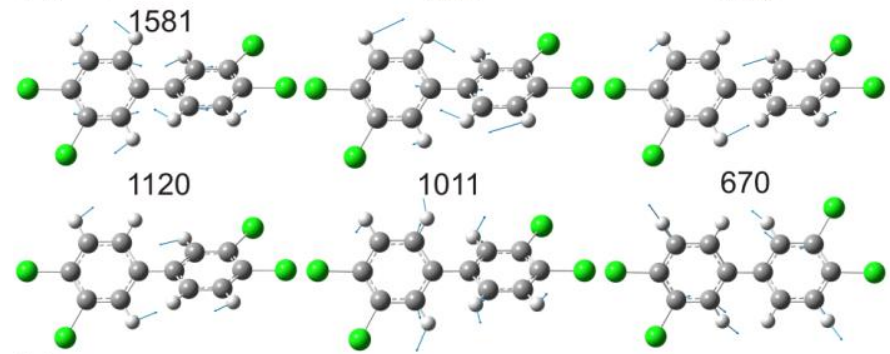

1011

670
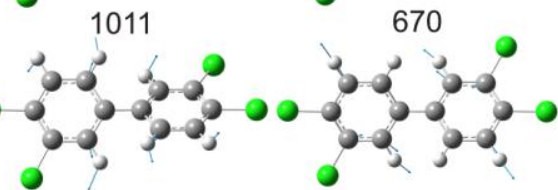

(b) $\mathrm{PCB} 77-\mathrm{SCH}_{3}$

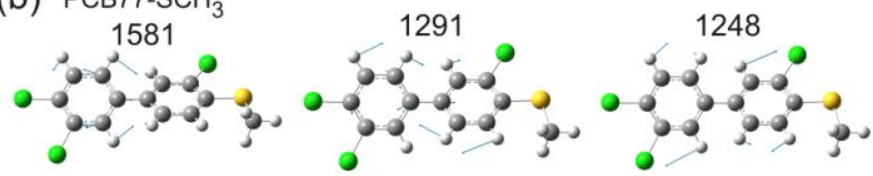

$$
1117 \quad 1014 \quad 674
$$

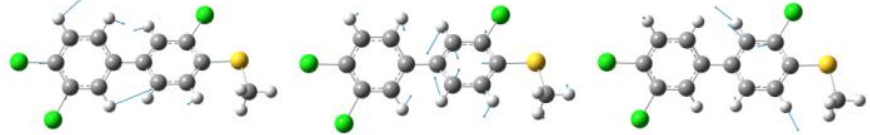

(c)

\begin{tabular}{|c|c|c|c|c|c|c|}
\hline \multicolumn{3}{|c|}{ PCB77 } & \multicolumn{3}{|c|}{ PCB77-SCH 3} & \multirow[b]{2}{*}{ assignment } \\
\hline Solid & SERS & Calc. & Solid & SERS & Calc. & \\
\hline 676 & 674 & 670 & 677 & 678 & 674 & $\overline{\mathrm{C}-\mathrm{Cl} \text { and ring stretch }}$ \\
\hline 1030 & 1027 & 1011 & 1031 & 1027 & 1014 & ring breathing/stretching \\
\hline 1136 & 1137 & 1120 & 1134 & 1128 & 1117 & $\mathrm{C}-\mathrm{H}$ bending/ring stretch \\
\hline 1245 & 1251 & 1249 & 1242 & 1246 & 1248 & $\mathrm{C}-\mathrm{H}$ wagging \\
\hline 1297 & 1280 & 1288 & 1297 & 1294 & 1291 & C-C bridge stretching \\
\hline 1597 & 1589 & 1581 & 1595 & 1586 & 1581 & ring stretching \\
\hline
\end{tabular}


Figure 4

(a) PCB77

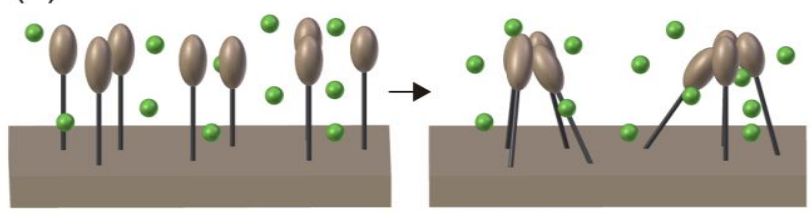

(b) a $\mathrm{PCB} 77-\mathrm{SCH}_{3}$
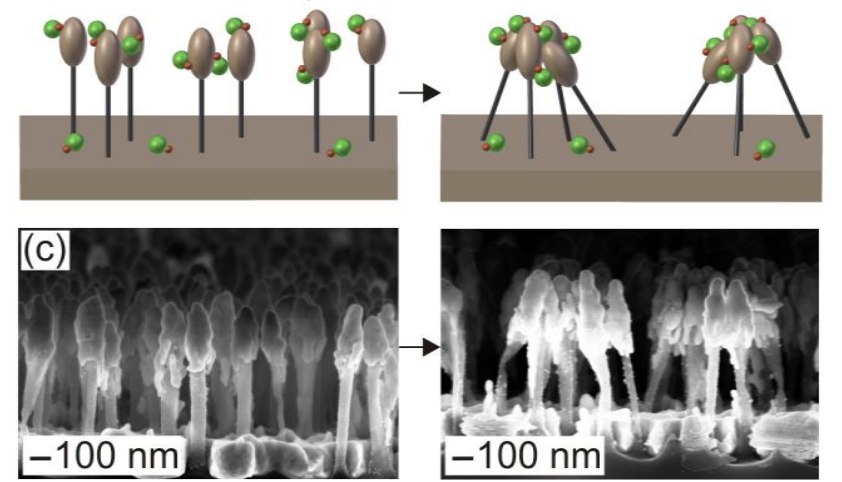
Figure 5

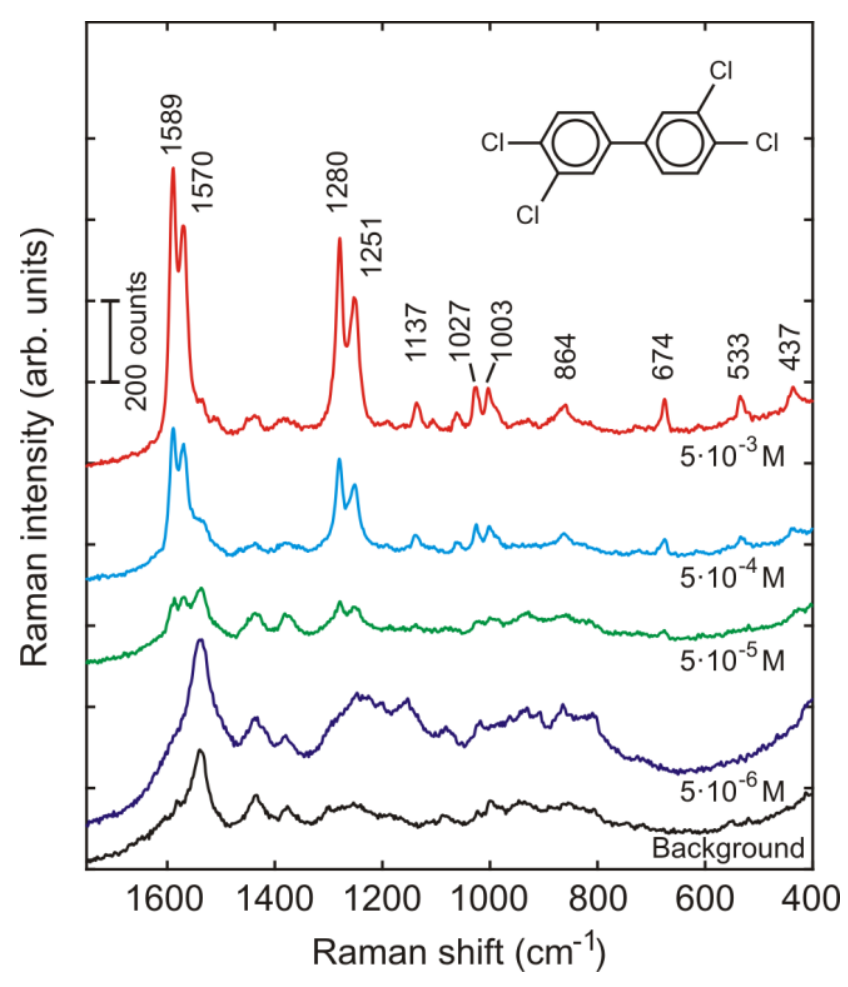


Figure 6

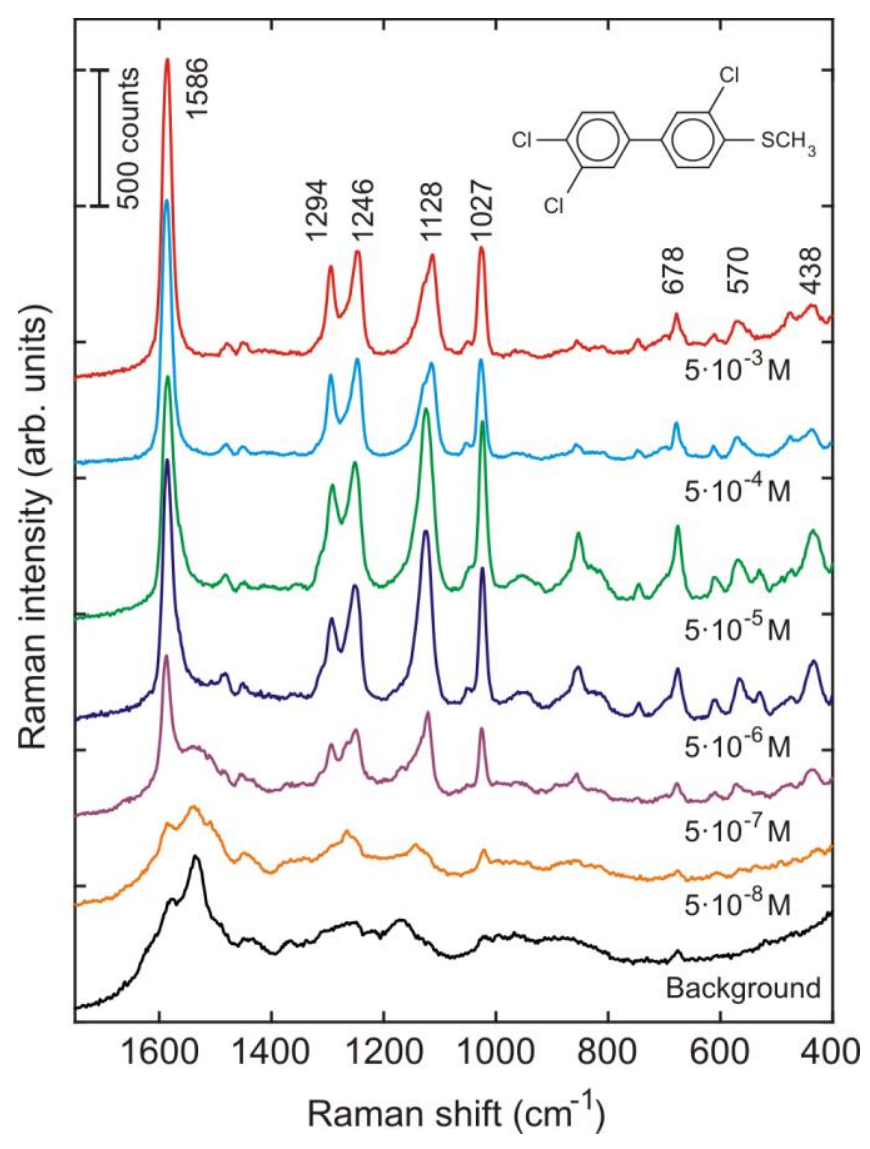


Figure 7

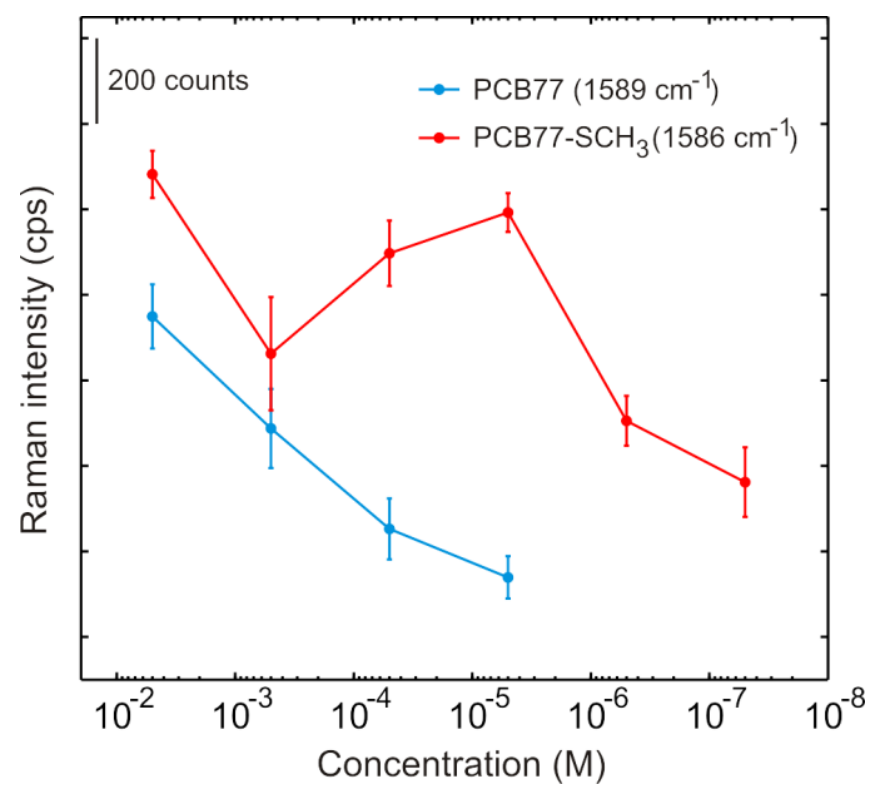

